\title{
STATISTICAL RESEARCH ON RAINFALL AND RIVER DISCHARGE PATTERNS OVER TIME FROM A HYDROLOGICAL PERSPECTIVE
}

\author{
MALARVIZHI, R. ${ }^{{ }^{*}}-$ RAVIKUMAR, G. $^{2}$ \\ ${ }^{1}$ Department of Civil Engineering, College of Engineering Guindy, Anna University, Sardar \\ Patel Road, Chennai 600025, Tamilnadu, India. \\ ${ }^{2}$ Centre for Water Resources, Department of Civil Engineering, College of Engineering Guindy, \\ Anna University, Sardar Patel Road, Chennai 600025, Tamilnadu, India \\ (e-mail: grk6617@gmail.com; phone: +91-98-4025-7426) \\ *Corresponding author \\ e-mail: babloomalar15@gmail.com; phone:+91-80-1246-0783 \\ (Received $13^{\text {th }}$ Sep 2020; accepted $8^{\text {th }}$ Feb 2021)
}

\begin{abstract}
Climate signals are the indicators of climate change evidence in a particular region or area, which can be witnessed through an erratic rainfall pattern showing less variability than usual which simultaneously affects the hydrological cycle of water systems in major. The behaviour of any weather pattern can be visualized by statistical analysis in combination with trend patterns. This study was made to draw the rainfall and river discharge variability of the Thamirabarani River, Tamilnadu, India through statistical analogy. The trend analysis was carried out by non-parametric Mann-Kendall, Spearman's Rho and Linear Regression Test for ten Rain Gauge stations and one Stream Gauge station from 1980 to 2018 (39 years). The results were interpreted for annual and seasonal patterns where seasonal includes Southwest monsoon, North-east monsoon, Winter and Summer periods respectively. This statistical analysis of weather parameters is a preliminary investigation for further research, through hydrological simulations, predictions and scenarios a better management and planning of water resources can be achieved in the Thamirabarani River basin, Tamilnadu, India.
\end{abstract}

Keywords: weather parameters, river basin, statistical test, trend analysis, temporal variation, spatial distribution, climate signals

\section{Introduction}

Across the world, scientists now agree that there is climate change due to anthropogenic activities. The phrase climate change has to be a priority on the list while developing planning and management of natural resources. It creates inequitable burden to the poor and developing countries as well as impacting the world's water resources. The projected future climatic scenarios indicate the rise in global temperatures from 1.4 to 5.8 degrees Celsius. Therefore, the slight shift in climate patterns of the $21^{\text {st }}$ century may be significant and disruptive whereas if it will be on the higher end of the spectrum it could be catastrophic. All the above framed contexts are the guidelines by IPCC SR15 report to be followed when it comes to research and investigations.

Rainfall is the major water resources for the earth which is collected in various forms as precipitation in various shapes and structures on the surface as well as ground sources without major losses. It is the fact that water is a naturally recycled resource but the spatial and temporal scales of its pattern has been changed in wide-range. For the sustainable development of planning and management of water resources primarily, the rainfall patterns have to be analyzed in different perspective. The accuracy in rainfall measurement have been increased by the scientific methods like remote sensing and 
automatic measurements etc. Before the validation, simulation, calibration and prediction of hydrological parameters such as rainfall and temperature, it is very necessary to understand the behavior of raw observed data. This real-time dataset statistical study has to be given precedence in any methodology with respect to water resources and its management. Because of the statistical analysis and trend prediction, the behavior of any weather parameter could be well understood in accordance with its periodical manner, extremities and also the causes. Rainfall and river discharge are interconnected as the water discharge is a dependent factor on the rainfall pattern, though both are separately observed in terms of data measurements. The impact of rainfall amount on river discharge shown through statistical analysis and trend prediction is the study to be discussed below along with the help literature review.

The precipitation trends of rainfall give immense results about the increase or decrease of trend pattern with the help of conventional Mann-Kendall, Mann-Kendall and Sen's slope estimator statistical hypothesis testing (Gajbhiye et al., 2016; Gocic and Trajkovic, 2013; Hussien et al., 2019). The trend prediction which can be attempted successfully through Mann-Kendall and Spearman's Rho Test of statistical analysis used to correlate the data in the form of monthly, seasonal and annual time series (Ahmad et al., 2015; Palanichamy and Sankaralingam, 2020). The spatial and temporal variation can be scaled down with the long-term rainfall records by the Mann-Kendall test that shows the trend patterns as well as the extremities (Anand and Karunanidhi, 2020). The statistical analysis can also be done with various number of hypothetical testing such as Linear Time series analysis, Mann-Kendall Z-statistics, Sen's slope estimator and Linear growth model along with combination of weather parameters for better understanding of the climate strategies (Bello et al., 2020; Pandit, 2016). The rainfall records or patterns of measurement not only show a trend in its variation but also conclude the abnormal conditions of the climate as signals for the long time period (Das and Tripathy, 2020). The prediction, fluctuations and anomalies can be investigated through trend patterns of rainfall which tends to accelerate the river discharge inferred through this spatio-statistical analysis of Auto Regressive Integrated Moving Average (ARIMA) approach (Dawood et al., 2020). The analysis of spatio-temporal trends of rainfall is done by Theil and Sen's Slope estimator test for rainfall magnitude as well as Inverse Weight Distance (IDW) through ArcGIS (Geographic Information System) software to predict the variation in trend patterns (Diop et al., 2016). The rainfall trend prediction through non-parametric Mann-Kendall and Sen's slope estimator testing shows significant variation that portraits the spatial scale by interpolation techniques in Quantum GIS (Geographic Information System) software for the management studies (Meshram et al., 2018).

The rainfall trend pattern sometimes helps us to understand the efficiency of result in terms of quantity like its impact on regional or global climate scales by the methods such as Mann Kendal's rank correlation statistics and wavelet analysis (Nikhil Raj and Azeez, 2012). Rainfall and temperature are the dependent factors that never fails to show their impacts on each other, which is evident through the geo-statistical and descriptive statistics and also the clear signature of change in climate through observed data will be making the adaptation and mitigation measures (Savo et al., 2012; Talib et al., 2021). The annual and seasonal trends have been predicted for the temperature of long-term dataset using Modified Mann-Kendall and CUMSUM statistical testing by $95 \%$ of confidence interval suggesting mitigation measures for the recovery of water resources (Singh et al., 2015). An accuracy rate increases when there is an update in dataset likewise the satellite data using Artificial Neural Network (ANN) will improve the trend prediction and spatio- 
temporal variations in different aspects in statistical testing (Sobral et al., 2020). The trend analysis of rainfall will be more informative when it is compared with statistical and graphical methods, also in parallel used to make decisions in terms of trend as increasing or decreasing pattern (Rathnayake, 2019). Presence of two or more variable predicts widely where at least one independent and two or more dependent variables will be leading to proper construction of trend patterns as well as the variation and changes happening in time-scales of climatic data (Nyokabi et al., 2017). The precipitation trend variation gradually affects the water discharge trends which are noticeable in the case of Mann-Kendall and Pettit abrupt statistical testing and then leads to double mass curve and regression analysis for the prediction of quantitative impacts of climate change ( $\mathrm{Li}$ et al., 2020). With the one parameter like stream flow it is possible to predict the trend pattern through the statistical analysis, which will be helpful in decision making when it comes to spatial and temporal scales of urbanized watersheds (Bhaskar et al., 2020). The trend analysis of stream flow prediction with respect to monthly, seasonal and annual pattern of mean values showed the variations and also used in change point analysis (Kale and Sönmez, 2019). The spatio-temporal trends, variability and teleconnections are analyzed using both parametric and non-parametric statistical testing with the help of gridded rainfall data. As per the inference, the study will draw down the large scale impacts of Sea Surface Temperature (SST) through this trend analysis (Sah et al., 2021). The Rainfall and its runoff plays a major role with other hydro-climatic variables while the trend patterns of rainfall and runoff using Mann-Kendall test and Sen's slope estimator has taken into an account primarily for the prediction of annual and seasonal variations and its impacts on other hydrological parameters respectively (Solaimani et al., 2021; Alifujiang et al., 2021). Therefore, this study has been framed by authors to predict the trend pattern in spatio-temporal scales for Rainfall and River discharge in Thamirabarani River, Tamilnadu, India using Mann-Kendall, Spearman's Rho and Linear Regression test in reference to highlighted literature.

\section{Study area}

Thamirabarani River was selected as the focus element in this study. This river is one of the oldest systems in Tamil Nadu, India. The river is short but it is a perennial source in the Southern part of Tamilnadu, India. Irrigation development is a major source of income for the people living adjoining the Thamirabarani river. Hence, Thamirabarani River was chosen to examine the behavior of extremities with a reference to statistical perspective. It originates from the peaks of Pothigai hills on the Eastern slopes of the Western Ghats at an altitude of $2000 \mathrm{~m}$ and confluences with the Bay of Bengal at Gulf of Mannar, India. It is the lifeline for the people of Tirunelveli and Thoothukudi districts, Tamilnadu, India. The total area of the basin is $5,650 \mathrm{~km}^{2}$, of which hilly portion is $688 \mathrm{~km}^{2}$. The basin is situated between $8^{\circ} 21^{\prime} \mathrm{N}$ and $9^{\circ} 13^{\prime} \mathrm{N}$ Latitudes and $77^{\circ} 10^{\prime} \mathrm{E}$ and $78^{\circ} 8^{\prime} \mathrm{E}$ Longitudes. It enjoys the benefit of both the Southwest and Northeast monsoons as it receives supply from the rainfall over Western Ghats, India. The river traverses about $125 \mathrm{~km}$ through Thirunelveli and Thoothukudi districts in Tamil Nadu, India.

The catchment area is divided into seven sub-basins as Upper Thamirabarani, Lower Thamirabarani, Chittar, Gadananadhi, Uppodai, Manimuttar and Pachaiyar as presented on the map (Fig. 1). It has 33 rain gauge stations throughout its basin at present. Amongst that only 10 out of 33 rain gauge stations (Fig. 2) are selected for an analysis, due to the data reliability in observed rainfall measurements for a long-term period of 39 years. The 
selected rain gauge stations were spatially distributed throughout the basin without any bar adjustment in its topographic features which plays vital role in rain gauge station placements. In addition to this, there is presence of two full climatic stations one at upstream (Cheranmadevi), the other at the middle of the basin (Kalampatti) as well as one stream gauge station (Murappanadu) at downstream (Fig. 2). The one major critical point station named Murappanadu stream gauge was selected as it joins two major stream order at this point before the outlet of basin enters the Bay of Bengal. Also, the block map for Thamirabarani basin (Fig. 3) is represented below for the study reference.

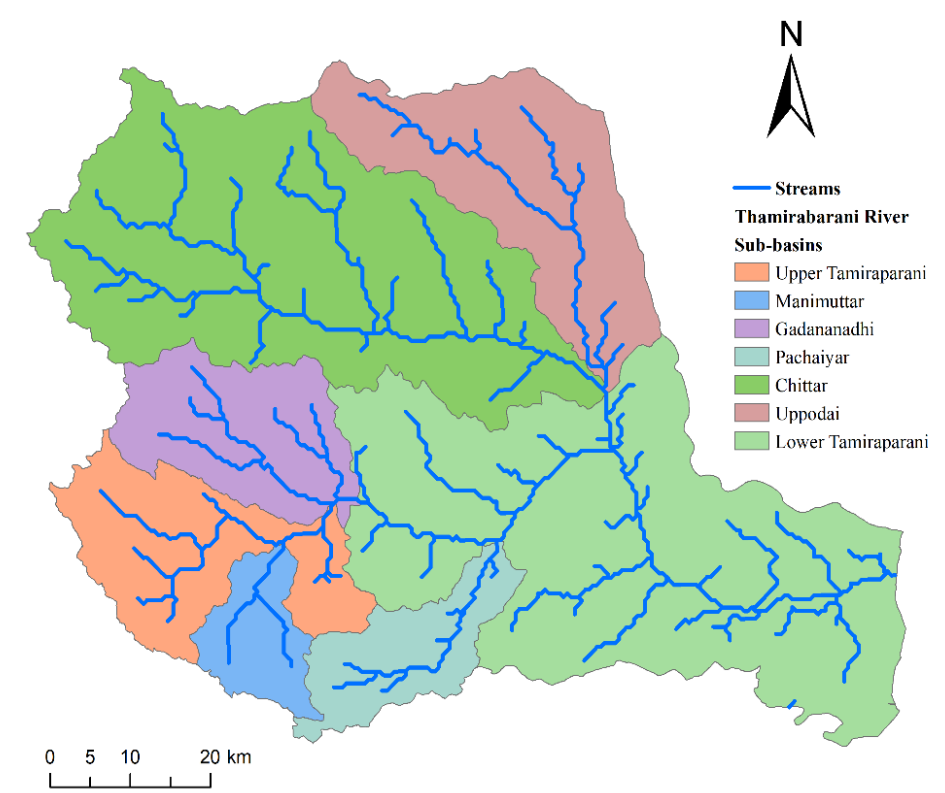

Figure 1. Thamirabarani River and its sub-basins

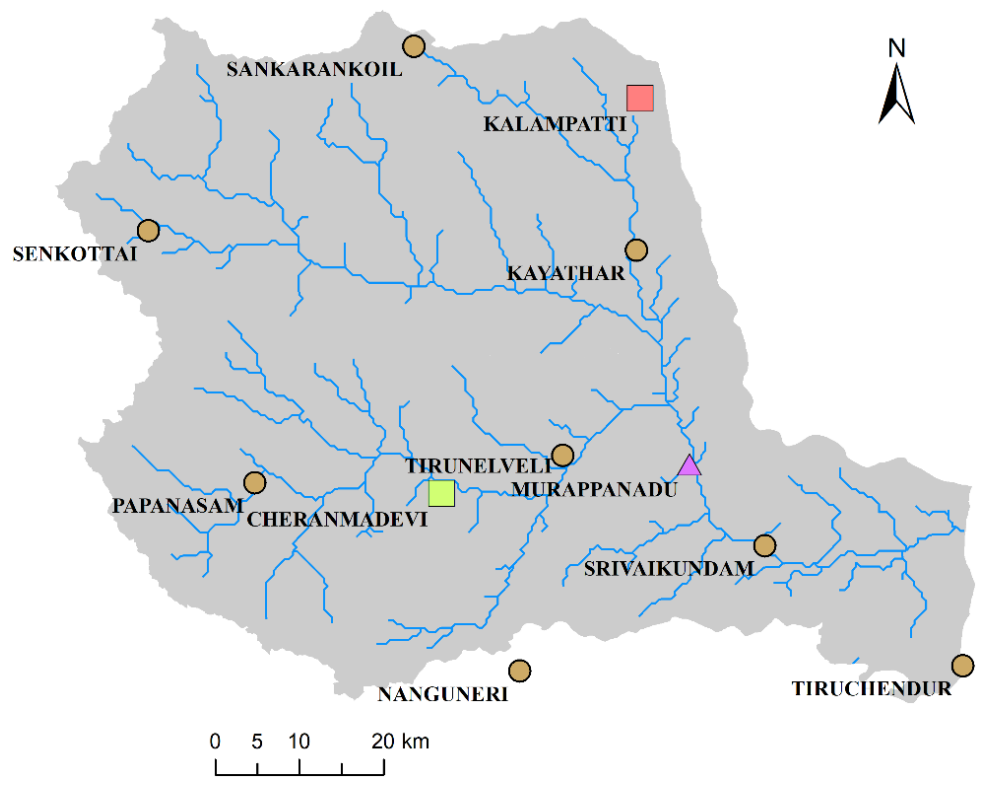

Figure 2. Rain gauge station locations in Thamirabarani River basin 


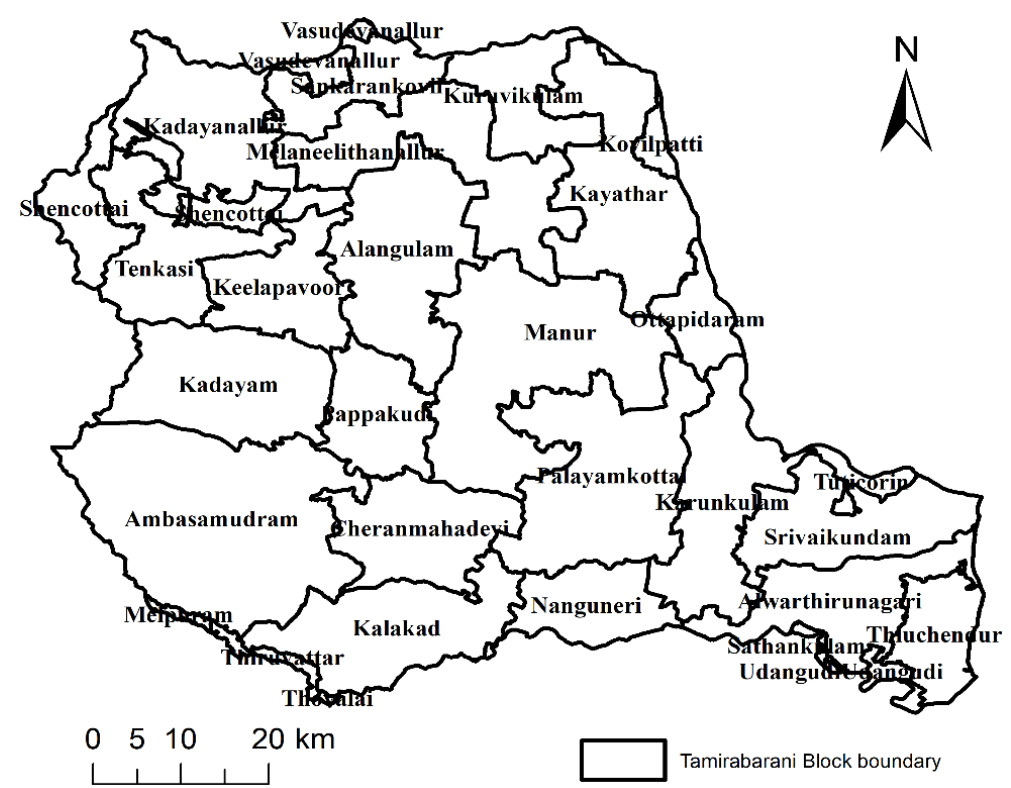

Figure 3. Block boundaries in Thamirabarani River basin

The rain gauge stations under respective sub-basins are listed out in Table 1 and its salient features for the study area of Thamirabarani river basin is compiled in Table 2. As per the availability of raw observed data obtained from Central Water Commission (CWC), India and Institute for Water Studies (IWS), Taramani, and Chennai for 39 years (1980-2018), the rain gauge stations were chosen in accordance with the installation period and utilized below for the methodology.

Table 1. Stream gauge and rain gauge stations under sub-basin zones

\begin{tabular}{c|c|c}
\hline Zones & Sub-basin & Rain gauge station \\
\hline $\mathbf{1}$ & Upper Thamirabarani & Papanasam \\
\hline $\mathbf{2}$ & Lower Thamirabarani & $\begin{array}{c}\text { Murappanadu - Stream gauge station } \\
\text { Srivaikundam } \\
\text { Tiruchendur }\end{array}$ \\
\hline $\mathbf{3}$ & Gadananadhi & Cheranmahadevi - Full Climate Station (FCS) \\
\hline $\mathbf{4}$ & Manimuttar & Tirunelveli \\
\hline $\mathbf{5}$ & Pachaiyaar & Senkottai \\
\hline $\mathbf{6}$ & Chittar & $\begin{array}{c}\text { Sankarankoil } \\
\mathbf{7}\end{array}$ \\
& Uppodai & Kalampatti - Full Climate Station (FCS) \\
\end{tabular}

The Cheranmahadevi and Kalampatti are the only weather stations observing all the possible weather parameters for thamirabarani river basin maintained by Central Water Commission (CWC), India and the Papanasam station is installed with automatic rainfall measurements by Institute for Water Studies (IWS), Taramani and Chennai, India. 
Table 2. The geographic details of Thamirabarani River basin

\begin{tabular}{c|c|c|c|c|c|c}
\hline $\begin{array}{c}\text { S. } \\
\text { No }\end{array}$ & $\begin{array}{c}\text { Rain gauge station } \\
\text { name }\end{array}$ & District & Tasil/Taluk & Latitude & Longitude & $\begin{array}{c}\text { Altitude } \\
\text { (masl) }\end{array}$ \\
\hline $\mathbf{1}$ & Cheranmahadevi & Tirunelveli & Cheranmahadevi & $08^{\circ} 41^{\prime} 17^{\prime \prime}$ & $77^{\circ} 33^{\prime} 49^{\prime \prime}$ & 63 \\
$\mathbf{2}$ & Kalampatti & Thoothukudi & Kayathar & $09^{\circ} 08^{\prime} 48^{\prime \prime}$ & $77^{\circ} 47^{\prime} 23^{\prime \prime}$ & 78 \\
$\mathbf{3}$ & Kayathar & Thoothukudi & Kayathar & $08^{\circ} 56^{\prime} 50^{\prime \prime}$ & $77^{\circ} 46^{\prime} 33^{\prime \prime}$ & 62 \\
$\mathbf{4}$ & Nanguneri & Tirunelveli & Nanguneri & $08^{\circ} 29^{\prime} 48^{\prime \prime}$ & $77^{\circ} 38^{\prime} 47^{\prime \prime}$ & 106 \\
$\mathbf{5}$ & Papanasam & Tirunelveli & Ambasamudram & $08^{\circ} 42^{\prime} 02^{\prime \prime}$ & $77^{\circ} 21^{\prime} 42^{\prime \prime}$ & 8 \\
$\mathbf{6}$ & Sankarankoil & Tirunelveli & Sankarankoil & $09^{\circ} 10^{\prime} 04^{\prime \prime}$ & $77^{\circ} 32^{\prime} 12^{\prime \prime}$ & 138 \\
$\mathbf{7}$ & Senkottai & Tirunelveli & Senkottai & $08^{\circ} 58^{\prime} 18^{\prime \prime}$ & $77^{\circ} 14^{\prime} 54^{\prime \prime}$ & 156 \\
$\mathbf{8}$ & Srivaikundam & Thoothukudi & Srivaikundam & $08^{\circ} 37^{\prime} 45^{\prime \prime}$ & $77^{\circ} 54^{\prime} 44^{\prime \prime}$ & 19 \\
$\mathbf{9}$ & Tiruchendur & Thoothukudi & Tiruchendur & $08^{\circ} 29^{\prime} 56^{\prime \prime}$ & $78^{\circ} 07^{\prime} 30^{\prime \prime}$ & 14 \\
$\mathbf{1 0}$ & Tirunelveli & Tirunelveli & Manur & $08^{\circ} 43^{\prime} 40^{\prime \prime}$ & $77^{\circ} 41^{\prime} 41^{\prime \prime}$ & 33 \\
$\mathbf{1 1}$ & Murappanadu & Thoothukudi & Srivaikundam & $08^{\circ} 43^{\prime} 01^{\prime \prime}$ & $77^{\circ} 49^{\prime} 54^{\prime \prime}$ & 26 \\
\hline
\end{tabular}

\section{Materials and methods}

\section{Rainfall and river discharge analysis}

With the available monthly data, the rainfall is categorized for four seasons faced by the study area i.e. (I) Pre-monsoon (March - May) which is also referred as summer or mango showers, (II) Monsoon (June-September) as South-west monsoon, (III) Postmonsoon (October-December) as North-east monsoon and (IV) Winter (December February). Therefore, these four seasons are grouped into Seasonal pattern and altogether as an Annual Rainfall pattern. This rainfall pattern is subjected to be applied for both rain gauge and stream gauge stations where the former measures rainfall in $\mathrm{mm}$ and the latter does river discharge in $\mathrm{m}^{3} / \mathrm{s}$. The preliminary factors of statistical test such as maximum, minimum, mean, standard deviation, variance, coefficient of variation, skewness and kurtosis were determined for both annual and seasonal datasets to study the behavior of spatial as well as temporal scale changes in the rainfall amount and pattern for the river basin. The statistical testing of river discharge data will predict the hydrological causes through the trend occurrence in the monthly, seasonal and annual scenarios.

\section{Trend prediction}

\section{Mann-Kendall test}

The Mann-Kendall test is a non-parametric (distribution-free) test which means there is no requirement of assumptions unlike linear regression analysis. This test is to assess whether the trend pattern is upward or downward monotonically over the period of time and is best viewed as exploratory analysis. It is most appropriately used to identify stations where changes are significant or of large magnitude and to quantify these findings. According to literature review, the best fitted method to do statistical analysis of weather parameters is Mann-Kendall as the major test done at first further acts as a dependent variable for other detection tests. The observed measurements over time are arranged in an order of $\mathrm{x}_{1}, \mathrm{x}_{2} \ldots \mathrm{x}_{\mathrm{n}-1}$ as $\mathrm{x}_{\mathrm{i}}$ and $\mathrm{x}_{2}, \mathrm{x}_{3} \ldots \mathrm{x}_{\mathrm{n}}$ as $\mathrm{x}_{\mathrm{j}}$ where the number of times represented as $1,2,3 \ldots \mathrm{n}$ respectively. The sign of all possible differences $\left(\mathrm{x}_{\mathrm{j}}\right.$ - 
$\left.\mathrm{x}_{\mathrm{i}}\right)$ where $\mathrm{j}>\mathrm{I}$ are determined. The $\operatorname{sgn}\left(\mathrm{x}_{\mathrm{j}}-\mathrm{x}_{\mathrm{i}}\right)$ is an indicator function and the values are compared using Equation 1:

$$
\operatorname{sgn}\left(x_{j}-x_{i}\right)=\left\{\begin{array}{c}
+1, \text { if } x_{j}>x_{i} \\
0, \text { if } x_{j}=x_{i} \\
-1, \text { if } x_{j}<x_{i}
\end{array}\right.
$$

The Mann-Kendall's statistic (S) was determined as the difference between the number of positive and negative differences by Equation 2:

$$
S=\sum_{i=1}^{n-1} \sum_{j=i+1}^{n} \operatorname{sgn}\left(x_{j}-x_{i}\right)
$$

where $\mathrm{n}$ is the number of collected data samples. The S-test have to be computed with variance if $\mathrm{n}>10$. Hence, the variance of $\mathrm{S}$ was calculated by Equation 3:

$$
\operatorname{Var}(S)=\frac{1}{18}\left[n(n-1)(2 n+5)-\sum_{p=1}^{g} t_{p}\left(t_{p}-1\right)\left(2 t_{p}+5\right)\right]
$$

where ' $g$ ' is the number of tied groups i.e. a set of data sample having the same value and $t_{p}$ is the number of data samples in the $\mathrm{p}^{\text {th }}$ tied group. The MK test statistic $(Z)$ was determined by Equation 4:

$$
z_{M K}=\left\{\begin{array}{c}
\frac{s-1}{\sqrt{\operatorname{Var}(S)}} \text { if } S>0 \\
0 \text { if } S=0 \\
\frac{s+1}{\sqrt{\operatorname{Var}(S)}} \text { if } S<0
\end{array}\right.
$$

The positive (negative) value will show the trend to increase (decrease) over time and the trend is detected eventually as per the classification requirements.

\section{Spearman's rho test}

Spearman's rank correlation coefficient is the statistical measure between the two datasets to ensure the strength of its link. This test comes under non-parametric methods and also used to correlate two variables in a group of data. As said here, the observed data include one with time in years and the other as rainfall time series data in month per millimeters. Similar to Mann-Kendall test, the numbers of time series data are replaced by ranks in order. The test statistic $\left(\rho_{\mathrm{s}}\right)$ was designed by Siegel and Castellan framed as Equation 5:

$$
\rho_{s}=\frac{s_{x y}}{\sqrt{S_{x} s_{y}}}
$$

where $\rho_{\mathrm{s}}$ is the correlation coefficient, $S_{x}=\sum_{i=1}^{n}\left(X_{i}-\bar{X}\right)^{2}, S_{y}=\sum_{i=1}^{n}\left(Y_{i}-\bar{Y}\right)^{2}$, $S_{x y}=\sum_{i=1}^{n}\left(X_{i}-\bar{X}\right)^{2}\left(Y_{i}-\bar{Y}\right)^{2}$ and $X_{\mathrm{i}}$ (time), $\mathrm{Y}_{\mathrm{i}}$ (variable of interest), $\mathrm{x}$ and $\mathrm{y}$ refer to the ranks $\left(\mathrm{x}, \mathrm{y}, \mathrm{S}_{\mathrm{x}}\right.$, and $\mathrm{S}_{\mathrm{y}}$ have the same values in analyzing the trend). For long-term samples, the quantity $\rho_{\mathrm{s}}=(\mathrm{n}-1)^{1 / 2}$ is approximately normally distributed with mean of 0 
and variance of 1 (critical test statistic values for various significance levels can be obtained from probability tables).

\section{Linear regression test}

Regression analysis also comes under statistical technique that attempts to explore and model the relationship between two or more variables. The model here designed and tested are simple linear regression in which one as independent variable (regressors or predictors) and the other as dependent variable (response) tends to produce straight line with the help of residuals formed. The linear regression formula is represented below in Equation 6:

$$
E(Y)=\beta_{\circ}+\beta_{1} x
$$

where $\beta_{0}=$ intercept and $\beta_{1}=$ slope of the regression coefficients followed by $\mathrm{x}$ as independent variable and $\mathrm{Y}$ as dependent variable. The slope, $\beta_{1}$, can be interpreted as the change in the mean value of $Y$ for a unit change in $\mathrm{x}$. The random error term, $\epsilon$, is assumed to follow the normal distribution with a mean of 0 and variance of $\sigma^{2}$. Since $Y$ is the sum of this random term and the mean value, $\mathrm{E}(\mathrm{Y})$, which is a constant, the variance of $\mathrm{Y}$ at any given value of $\mathrm{x}$ is also $\sigma^{2}$. Therefore, at any given value of $\mathrm{x}$, say $\mathrm{x}_{i}$, the dependent variable $\mathrm{Y}$ follows a normal distribution with a mean of $\beta_{0}+\beta_{1} x_{i}$ and a standard deviation of $\sigma$.

This linear regression is an inbuilt test for both Mann-Kendall and Spearman's Rho test and the main purpose of this test is to produce the trend line for the given data samples with the help of mean and variance. It is the basic method for all statistical analysis and models. Therefore, this method of hypothetical testing is applied to the weather parameters in correlation namely, Rainfall and River discharge will draw the trends. Further, its prediction has been projected for the deep down micro-level studies and its measures in the hydrological aspects.

\section{Results and discussion}

\section{Statistical analysis of rainfall}

The statistical characteristics are calculated for the best fit of models which is considered to be the preliminary stage in statistical testing. There are various mathematical statistic formulations available in that only eight factors namely, minimum, maximum, mean, standard deviation, variance, co-efficient of variation, skewness and kurtosis are selected as the most suited parameters in statistics for hydrometeorological variables such as rainfall.

The graphical representation of basic factors calculated as descriptive statistics such as minimum, maximum, mean and standard deviation of annual rainfall data are presented (Fig. 4). From the graph, it has been clearly recorded that the maximum annual rainfall is at Papanasam station $(6131 \mathrm{~mm})$ which is located at upstream side and the minimum annual rainfall is at Kayathar station $(12.2 \mathrm{~mm})$ at downstream side of the basin. Though, the annual mean rainfall varies from $1511.1 \mathrm{~mm}$ for Senkottai station to $573.2 \mathrm{~mm}$ for Tirunelveli station whereas the fluctuation is too great in terms of spatial and temporal scales. Similarly, the standard deviation with lesser value is closer to mean 
at Srivaikundam station $(221.6 \mathrm{~mm})$ and the larger value is the most normally distributed one at Papanasam station $(913.8 \mathrm{~mm})$.

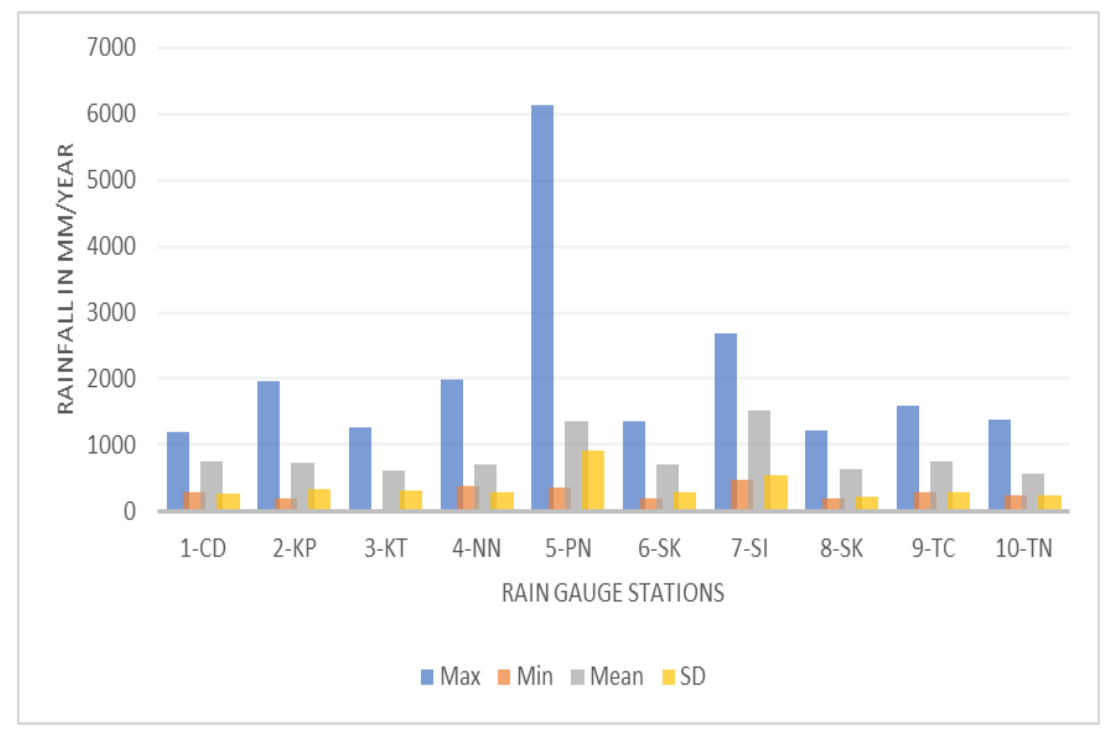

Figure 4. Annual rainfall of ten rain gauge stations and its four statistical factors

The confined eight statistical factors are formulated and calculated as parameters of statistical testing for all the ten rain gauge stations with respect to annual and seasonal pattern, the values are presented in Table 3.

The other four minor parameters such as variance, coefficient of variation, skewness and kurtosis are all dependent variables of the former statistics calculations which are explained above (Fig. 4). Variance is the square of the standard deviation the results in Table 3 show that higher variance values are far away from the mean and the lower one is closer to it.

As per Table 3, the coefficient of variation for annual rainfall amount varies from $66.7 \%$ in Papanasam station to $33.1 \%$ in Cheranmahadevi station. This statistical property is used when the data set is widely distributed by its mean then it can replace standard deviation while the $\mathrm{CV}$ values less than one are represented as low-variance and greater than one as high-variance that are exponentially distributed system. So, the annual rainfall amount is within the range of low-variance for both the stations. Almost all the stations and rainfall patterns both annual as well as seasonal are under positive values except for two, which indicates that they are skewed to the right in the normal distribution curve. The rainfall during annual as well as north-east monsoon (NEM) period in Papanasam station and rainfall during summer (SMR) in Nanguneri station were noticed as more skewed one. Most of the skewness coefficient values are identical to or nearly identical to zero representing that the data falls under normal distribution case. In case of kurtosis coefficient, the values lesser than three tends to be the flattened curve in normal distribution and greater values than three are replaced to Laplace distribution. The kurtosis property purely depends on the data set and here, the Papanasam station exhibits the higher value says that the peak values are the outliers to normal distribution and can be flattened by Laplace distribution. So, the peak values greater than three are in 13 out of 50 station points as outliers which can be corrected in Mann-Kendall test. 
Table 3. Statistical characterization of rainfall data

\begin{tabular}{|c|c|c|c|c|c|c|c|c|c|c|}
\hline Sl. No & Rainfall stations & $\begin{array}{l}\text { Time } \\
\text { series }\end{array}$ & $\begin{array}{l}\text { Max } \\
(\mathbf{m m})\end{array}$ & $\begin{array}{c}\text { Min } \\
(\mathbf{m m})\end{array}$ & $\begin{array}{l}\text { Mean } \\
(\mathbf{m m})\end{array}$ & \begin{tabular}{|c|}
$\begin{array}{c}\text { Standard } \\
\text { deviation } \\
(\mathrm{mm})\end{array}$ \\
\end{tabular} & Variance & $\begin{array}{c}\text { Coefficient } \\
\text { of variation }\end{array}$ & Skewness & Kurtosis \\
\hline \multirow{5}{*}{1} & \multirow{5}{*}{ Cheranmahadevi } & ANNUAL & 1190.6 & 278.3 & 750.97026 & 255.08247 & 65067.06 & 33.96705 & -0.26387 & -0.68641 \\
\hline & & SWM & 219.2 & 0 & 70.90436 & 46.88552 & 2198.25 & 66.12501 & 0.84964 & 1.19033 \\
\hline & & NEM & 913.64 & 195.8 & 485.86564 & 203.53673 & 41427.2 & 41.89157 & 0.37464 & -0.82444 \\
\hline & & WNT & 269.5 & 0 & 55.38795 & 67.14279 & 4508.15 & 121.22275 & 1.82416 & 2.90625 \\
\hline & & SMR & 556.8 & 13 & 138.81231 & 96.28804 & 9271.39 & 69.36564 & 2.30288 & 8.45497 \\
\hline \multirow{5}{*}{2} & \multirow{5}{*}{ Kalampatti } & ANNUAL & 1959.63 & 183.06 & \begin{tabular}{|l|}
739.60821 \\
\end{tabular} & 325.47771 & 105935.74 & 44.00677 & 1.41522 & 4.46048 \\
\hline & & SWM & 861.15 & 36.72 & 147.36897 & 165.44794 & 27373.02 & 112.26782 & 3.2734 & 11.67695 \\
\hline & & NEM & 848.63 & 110.42 & 413.26256 & 163.5359 & 26743.99 & 39.57191 & 0.23367 & 0.01874 \\
\hline & & WNT & 251.33 & 0 & 51.4841 & 63.28029 & 4004.39 & 122.91229 & 1.64741 & 2.13664 \\
\hline & & SMR & 357.58 & 12.95 & 127.49256 & 84.83762 & 7197.42 & 66.54319 & 1.26933 & 1.02199 \\
\hline \multirow{5}{*}{3} & \multirow{5}{*}{ Kayathar } & ANNUAL & 1267.7 & 12.2 & 621.39795 & 307.12609 & 94326.44 & 49.42502 & \begin{tabular}{|l|}
-0.21749 \\
\end{tabular} & 0.08799 \\
\hline & & SWM & 383 & 0 & 85.63077 & 84.83089 & 7196.28 & 99.0659 & 1.40267 & 2.40541 \\
\hline & & NEM & 802 & 0 & 399.48 & 232.81809 & 54204.26 & 58.28029 & 0.1674 & -0.66574 \\
\hline & & WNT & 118.5 & 0 & 21.01282 & 29.78485 & 887.14 & 141.7461 & 2.04252 & 4.41538 \\
\hline & & SMR & 454 & 0 & 115.27435 & 93.46954 & 8736.56 & 81.08442 & 1.23594 & 3.0657 \\
\hline \multirow{5}{*}{4} & \multirow{5}{*}{ Nanguneri } & ANNUAL & 1983.6 & 381 & 697.53333 & 280.78571 & 78840.61 & 40.25409 & 2.63262 & 10.85948 \\
\hline & & SWM & 251.5 & 2.1 & 79.44615 & 46.84578 & 2194.53 & 58.96544 & 1.17935 & 3.52142 \\
\hline & & NEM & 1129.5 & 147 & 437.92308 & 196.63616 & 38665.78 & 44.90199 & 1.3202 & 3.00585 \\
\hline & & WNT & 224 & 0 & 45.61026 & 51.63969 & 2666.66 & 113.21946 & 1.74823 & 3.4378 \\
\hline & & SMR & 751 & 7.2 & 134.55385 & 132.46313 & 17546.48 & 98.44619 & 3.28104 & 12.92621 \\
\hline \multirow{5}{*}{5} & \multirow{5}{*}{ Papanasam } & ANNUAL & 6131 & 362 & 1369.53846 & 913.81791 & 835063.17 & 66.72452 & 3.86418 & 19.65916 \\
\hline & & SWM & 780 & 6 & 186.84615 & 153.60573 & 23594.72 & 82.20974 & 2.07961 & 5.94568 \\
\hline & & NEM & 3130 & 190 & 850.58205 & 511.00197 & 261123.01 & 60.07674 & 2.65563 & 9.82523 \\
\hline & & WNT & 2070 & 0 & 156.04359 & 334.37772 & 111808.46 & 214.28482 & 5.22784 & 29.9223 \\
\hline & & SMR & 784 & 42 & 176.06667 & 139.74534 & 19528.76 & 79.37069 & 2.6712 & 9.17811 \\
\hline \multirow{5}{*}{6} & \multirow{5}{*}{ Sankarankoil } & ANNUAL & 1369 & 196.9 & 699.86704 & 292.13715 & 85344.13 & 41.74181 & 0.73928 & 0.16106 \\
\hline & & SWM & 288 & 9.2 & 76.30331 & 55.73158 & 3106.01 & 73.03954 & 1.64517 & 4.18178 \\
\hline & & NEM & 1181 & 76 & 427.06317 & 241.54348 & 58344.63 & 56.55953 & 1.4156 & 2.29228 \\
\hline & & WNT & 202.6 & 0 & 45.77409 & 53.22803 & 2833.2 & 116.2832 & 1.52113 & 2.01334 \\
\hline & & SMR & 387.2 & 20 & 150.72255 & 89.13748 & 7945.46 & 59.13995 & 0.66235 & 0.03501 \\
\hline \multirow{5}{*}{7} & \multirow{5}{*}{ Senkottai } & ANNUAL & 2689.7 & 474 & 1511.08979 & 552.54031 & 305302.67 & 36.56586 & \begin{tabular}{|l}
0.57437 \\
\end{tabular} & -0.28072 \\
\hline & & SWM & 1070.5 & 148.9 & 413.98569 & 224.80045 & 50535.53 & 54.30155 & 1.23589 & 1.10439 \\
\hline & & NEM & 2013 & 151 & 700.35572 & 333.48423 & 111211.65 & 47.61636 & 1.7108 & 5.13112 \\
\hline & & WNT & 450 & 0 & 101.44179 & 126.54623 & 16013.95 & 124.74762 & 1.49288 & 1.57487 \\
\hline & & SMR & 734.33 & 47.9 & 295.29992 & 185.61111 & 34452.54 & 62.85582 & 0.95804 & 0.22008 \\
\hline \multirow{5}{*}{8} & \multirow{5}{*}{ Srivaikundam } & ANNUAL & 1209.8 & 201.3 & 645.35442 & 221.60722 & 49109.79 & 34.33883 & 0.33953 & 0.20565 \\
\hline & & SWM & 179 & 0 & 64.22861 & 53.47743 & 2859.83 & 83.26103 & 0.74839 & -0.55635 \\
\hline & & NEM & 953.7 & 109.7 & 429.31662 & 213.34664 & 45512.21 & 49.68902 & 0.61916 & -0.20956 \\
\hline & & WNT & 239.2 & 0 & 47.49992 & 61.61936 & 3796.93 & 129.72571 & 1.72065 & 2.42218 \\
\hline & & SMR & 347.8 & 2 & 104.28427 & 76.18057 & 5803.47 & 73.05083 & 1.17828 & 1.5342 \\
\hline \multirow{5}{*}{9} & \multirow{5}{*}{ Tiruchendur } & ANNUAL & 1599.4 & 275.6 & 748.00056 & 285.09504 & 81277.75 & 38.11383 & 1.03674 & 1.33091 \\
\hline & & SWM & 109 & 0 & 30.67999 & 28.4335 & 808.44 & 92.67761 & 1.19992 & 0.76773 \\
\hline & & NEM & 1360.4 & 170.8 & 560.65897 & 267.16539 & 71377.35 & 47.65203 & 0.87972 & 0.7007 \\
\hline & & WNT & 297.7 & 0 & 65.82564 & 73.07422 & 5339.72 & 111.00622 & 1.51907 & 2.11038 \\
\hline & & SMR & 372.2 & 0 & 90.70459 & 84.68192 & 7179.62 & 93.36625 & 1.50382 & 2.43855 \\
\hline & & ANNUAL & 1391 & 248.8 & 573.19958 & 232.93238 & 54258.65 & 40.63784 & 1.1619 & 2.51419 \\
\hline & & SWM & 184.4 & 2 & 67.12051 & 49.18344 & 2419.01 & 73.27632 & 0.77042 & -0.04373 \\
\hline 10 & Tirunelveli & NEM & 876 & 112.2 & 361.83077 & 159.54201 & 25453.65 & 44.09299 & 0.92276 & 1.26563 \\
\hline & & WNT & 305.4 & 0 & 37.1641 & 65.17043 & 4247.18 & 175.35854 & 3.15812 & 10.45069 \\
\hline & & SMR & 316 & 2 & 107.08462 & 79.61844 & 6339.1 & 74.35096 & 1.10089 & 0.92111 \\
\hline
\end{tabular}

*SWM = south-west monsoon; NEM = north-east monsoon; WNT = winter; $\mathrm{SMR}=$ summer 
It is interpreted from the statistical properties that the rainfall amount contributed to the annual pattern in maximum by north-east monsoon (NEM) rainfall and minimum during winter (WNT) rainfall. The inference in whole from the descriptive statistics are the clear signature of rainfall data fluctuations and is now evident to proceed with the statistical testing using non-parametric methods for the trend analysis.

\section{Trend analysis}

\section{Annual rainfall trends}

With the analysis done through Mann-Kendall and Spearman's Rho test, annual rainfall data have predicted trends with the limit of confidence intervals such as 90, 95 and $99 \%$. The projected trends are correlated with both Mann-Kendall and Spearman's Rho test as one prediction for each rain gauge stations. This statistical hypothesis testing produced significantly both increasing (+ve) and decreasing trend (-ve) while there are also results with non-significant trends. The obtained annual rainfall trend results for Mann-Kendall and Spearman's Rho test are tabulated below in Table 4 and the visualization of results in terms of spatial scale with respect to rain gauge stations is shown in Figure 5.

Table 4. Statistical analysis on annual rainfall pattern

\begin{tabular}{|c|c|c|c|c|}
\hline \multirow{2}{*}{ S. No } & \multirow{2}{*}{ Rain gauge station } & \multicolumn{3}{|c|}{ Annual statistics } \\
\hline & & $\mathbf{Z}$ & $\rho$ & Trend \\
\hline 1 & Cheranmahadevi & 1.331 & 0.201 & No trend \\
\hline 2 & Kalampatti & 0.363 & 0.024 & No trend \\
\hline 3 & Kayathar & $1.887 * * *$ & $0.298 * * *$ & Increasing trend \\
\hline 4 & Nanguneri & 0.073 & 0.025 & No trend \\
\hline 5 & Papanasam & 0.847 & 0.164 & No trend \\
\hline 6 & Sankarankoil & $1.766^{* * *}$ & $0.281 * * *$ & Increasing trend \\
\hline 7 & Senkottai & $2.032 * *$ & $0.331 * *$ & Increasing trend \\
\hline 8 & Srivaikundam & 0.992 & 0.142 & No trend \\
\hline 9 & Tiruchendur & 0.847 & 0.146 & No trend \\
\hline 10 & Tirunelveli & $-1.694 * * *$ & $-0.289 * * *$ & Decreasing trend \\
\hline
\end{tabular}

Level of significance: $* * *=0.10, * *=0.05, *=0.01$

Table 4 shows the positive (increasing) trends, the Senkottai station showed significantly increasing trend at $5 \%$ of significance level wherein the Kayathar and Sankarankoil station had $10 \%$ of significance level in its increasing trend. Also, when it comes to negative (decreasing) trend, the only station subjected to significantly decreasing trend at $10 \%$ confidence level was Tirunelveli station in the whole basin for rainfall annually. The stations showing no trend are indicated with pictorial representation (Fig. 5).

With the same statistical testing of Mann-Kendall and Spearman's Rho test, the monthly rainfall data grouped under four seasons such as south-west and north-east monsoon, winter and summer, experienced by the study area were also applied seasonwise to detect the trend values. Hence, in Table 5 the results are analyzed for both 
monsoon seasons while in Table 6 results are recorded for both winter and summer seasons.

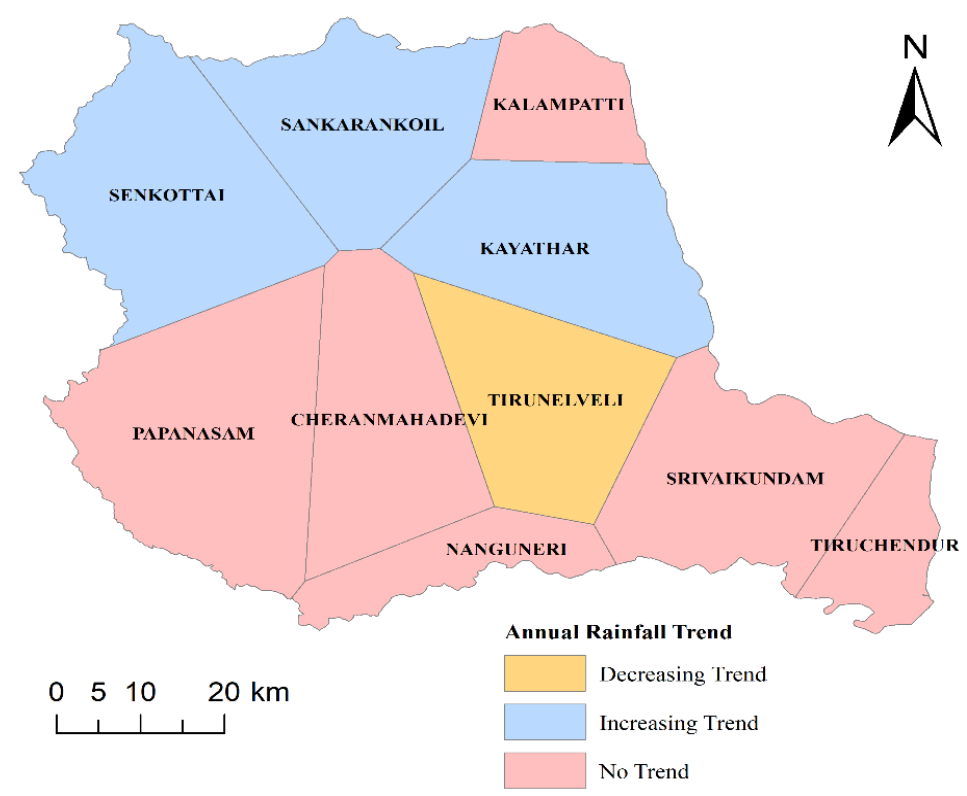

Figure 5. Spatial variation of annual trend distribution in Thamirabarani River basin seasonal rainfall trends

Table 5. Statistical analysis on seasonal patterns of SWM and NEM

\begin{tabular}{c|c|c|c|c|c|c|c}
\hline & & \multicolumn{6}{|c}{ Seasonal statistics } \\
\cline { 3 - 7 } S. No & \multirow{2}{*}{$\begin{array}{c}\text { Rain gauge } \\
\text { station }\end{array}$} & \multicolumn{2}{|c|}{$\begin{array}{c}\text { South-west monsoon } \\
\text { (SWM) }\end{array}$} & \multicolumn{3}{|c}{$\begin{array}{c}\text { North-east monsoon } \\
\text { (NEM) }\end{array}$} \\
\cline { 3 - 7 } & & $\mathbf{Z}$ & $\mathbf{\rho}$ & Trend & $\mathbf{Z}$ & $\boldsymbol{\rho}$ & Trend \\
\hline $\mathbf{1}$ & Cheranmahadevi & 0.919 & 0.15 & No Trend & $1.694 * * *$ & $0.267 * * *$ & Increasing Trend \\
$\mathbf{2}$ & Kalampatti & -1.113 & -0.239 & No Trend & 0.242 & 0.009 & No Trend \\
$\mathbf{3}$ & Kayathar & 0.423 & 0.104 & No Trend & $2.468^{* *}$ & $0.382^{* *}$ & Increasing Trend \\
$\mathbf{4}$ & Nanguneri & -0.823 & -0.151 & No Trend & 0.774 & 0.113 & No Trend \\
$\mathbf{5}$ & Papanasam & 1.21 & 0.217 & No Trend & 0.895 & 0.176 & No Trend \\
$\mathbf{6}$ & Sankarankoil & 1.089 & 0.184 & No Trend & 0.774 & 0.103 & No Trend \\
$\mathbf{7}$ & Senkottai & 0.871 & 0.141 & No Trend & $1.839 * * *$ & $0.282 * * *$ & Increasing Trend \\
$\mathbf{8}$ & Srivaikundam & -0.448 & -0.084 & No Trend & 0.992 & 0.151 & No Trend \\
$\mathbf{9}$ & Tiruchendur & -0.23 & -0.03 & No Trend & 0.968 & 0.152 & No Trend \\
$\mathbf{1 0}$ & Tirunelveli & -1.125 & -0.175 & No Trend & -1.125 & -0.177 & No Trend \\
\hline
\end{tabular}

Level of significance: $* * *=0.10, * *=0.05, *=0.01$

From the seasonal analysis, it is clearly shown that only increasing trend exists when it comes to seasonal basis of rainfall. The annual rainfall pattern of positive (increasing) trends have got an impact from seasonal rainfall, which is proven by this statistical analysis of Mann-Kendall and Spearman's Rho testing. With reference to Tables 5 and 6 , the test results show no variation in trend i.e. non-significant trend was noticed during south-west monsoon and winter season meaning that the rainfall amount in all rain 
gauge stations are in normal range. In the case of north-east monsoon season, the Cheranmahadevi and Senkottai station on the upstream side of the basin gets increasing trend for $10 \%$ confidence level while the Kayathar station got 5\% confidence level of increase in trend that must be taken into consideration. Similarly, during summer period there is an evidence of positive (increasing) trends with the same Cheranmahadevi station at $10 \%$ confidence level and the only noted rain gauge station of Sankarankoil have got increasing trend at $1 \%$ confidence level. The spatial scale representation of analyzed results showing only trends which are easier to interpret are mapped as northeast monsoon (Fig. 6a) and summer season (Fig. 6b) in two figures for better understanding of trend patterns in wide range throughout the basin.

Table 6. Statistical analysis on seasonal patterns of winter and summer

\begin{tabular}{|c|c|c|c|c|c|c|c|}
\hline \multirow{3}{*}{ S. No } & \multirow{3}{*}{$\begin{array}{c}\text { Rain gauge } \\
\text { station }\end{array}$} & \multicolumn{6}{|c|}{ Seasonal statistics } \\
\hline & & \multicolumn{3}{|c|}{ Winter } & \multicolumn{3}{|c|}{ Summer } \\
\hline & & $\mathbf{Z}$ & $\rho$ & Trend & $\mathbf{Z}$ & $\rho$ & Trend \\
\hline 1 & Cheranmahadevi & 0.46 & 0.122 & No Trend & $1.79 * * *$ & $0.309 * * *$ & Increasing Trend \\
\hline 2 & Kalampatti & 0.254 & 0.078 & No Trend & 0.798 & 0.108 & No Trend \\
\hline 3 & Kayathar & -0.302 & 0.169 & No Trend & 0.992 & 0.175 & No Trend \\
\hline 4 & Nanguneri & -0.073 & 0.067 & No Trend & 0.327 & 0.049 & No Trend \\
\hline 5 & Papanasam & 0 & 0.048 & No Trend & 1.198 & 0.212 & No Trend \\
\hline 6 & Sankarankoil & 0.593 & 0.16 & No Trend & $3.097 *$ & $0.496^{*}$ & Increasing Trend \\
\hline 7 & Senkottai & 0.532 & 0.13 & No Trend & 1.21 & 0.148 & No Trend \\
\hline 8 & Srivaikundam & -0.254 & 0.041 & No Trend & 0.169 & 0.024 & No Trend \\
\hline 9 & Tiruchendur & -0.593 & -0.009 & No Trend & 0.835 & 0.138 & No Trend \\
\hline 10 & Tirunelveli & -1.04 & -0.078 & No Trend & -0.302 & -0.052 & No Trend \\
\hline
\end{tabular}

Level of significance: $* * *=0.10, * *=0.05, *=0.01$

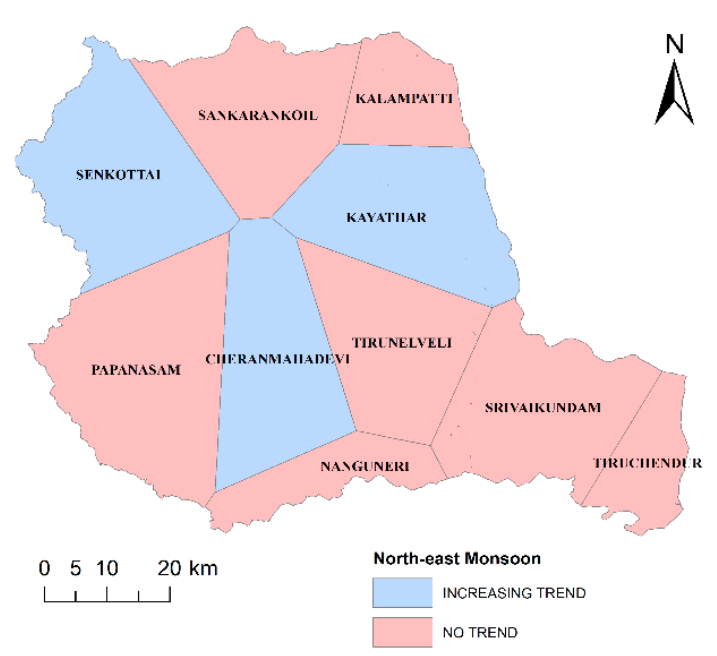

(a) North-east monsoon (October to December)

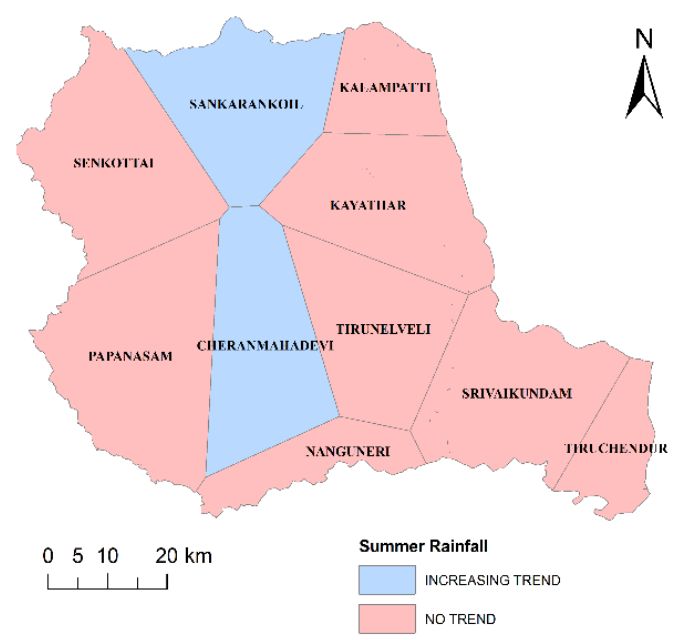

(b) Summer (March to May)

Figure 6. Spatial variation of seasonal trend distribution in Thamirabarani River basin annual, seasonal and monthly trends of river discharge 
River discharge is the stream flow or surface runoff of the basin. It totally depends on the amount of rainfall and it is one of the direct dependent variable of an independent parameter rainfall in terms of hydrology. So, the statistical characteristics can be overviewed through rainfall statistical analysis and the trend prediction is made through the Mann-Kendall and Spearman's Rho test for annual, seasonal and monthly trends considered to undergo deep down predictions.

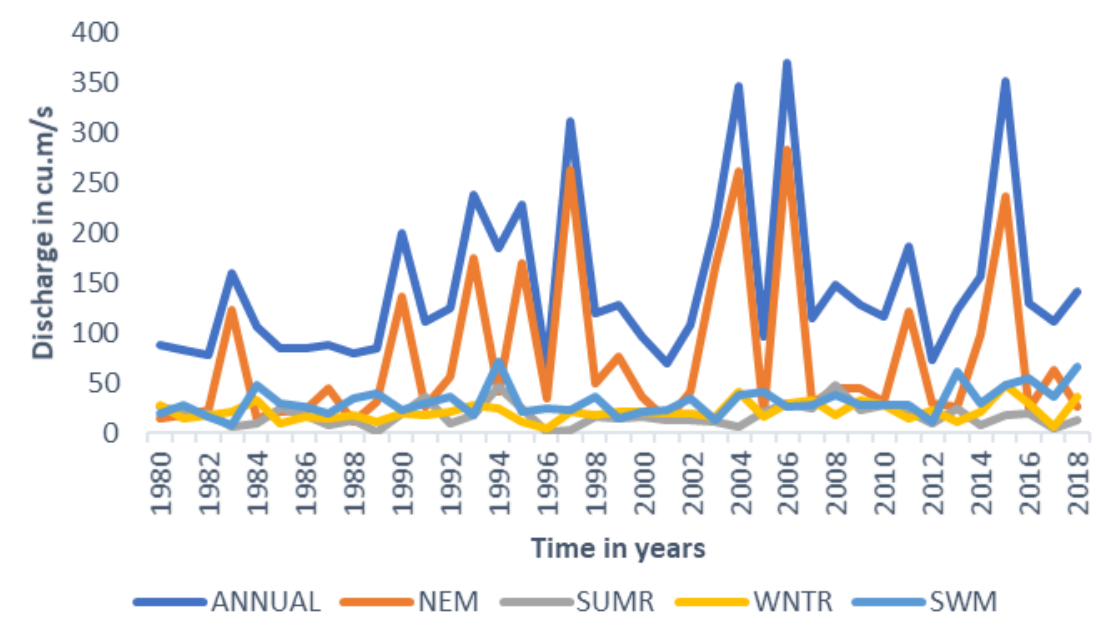

Figure 7. Temporal variation of Murappanadu station river discharge

Murappanadu stream gauge station is the only recorded discharge data in the basin located at the major stream order outlet. Due to its large scale contribution at that point of the basin, the recorded stream gauge data was analysed starting from annual to monthly discharge pattern for better trends in observation. The temporal scale representation of river discharge data (Fig. 7) from 1980-2018 concludes that the northeast monsoon impacts the discharge rate to increase and influence the annual discharge rate in intensive manner. The obtained test results and trend patterns for annual, seasonal and monthly time scales are tabulated in Tables 7 and 8.

Table 7. Annual and seasonal trend distribution for river discharge

\begin{tabular}{c|c|c|c|c}
\hline \multirow{2}{*}{ S. No } & Murappanadu stream gauge & \multicolumn{3}{|c}{ Statistical analysis } \\
\cline { 3 - 5 } & station & $\mathbf{Z}$ & $\boldsymbol{\rho}$ & Trend \\
\hline $\mathbf{1}$ & Annual rainfall & $2.298^{* *}$ & $0.37^{* *}$ & Increasing trend \\
$\mathbf{2}$ & South-west monsoon & $2.226^{* *}$ & $0.339^{* *}$ & Increasing trend \\
$\mathbf{3}$ & North-east monsoon & $1.621^{* * *}$ & $0.271^{* * *}$ & Increasing trend \\
$\mathbf{4}$ & Winter & 1.379 & 0.237 & No trend \\
$\mathbf{5}$ & Summer & -0.073 & 0.013 & No trend \\
\hline
\end{tabular}

Level of significance: $* * *=0.10, * *=0.05, *=0.01$

From Tables 7 and 8, the river discharge trend prediction shows an increasing trend in both annual and seasonal pattern. It is evident from the trend values that the impact of south-west and north-east monsoon seasonal pattern creates the weather event by 
increasing (positive) in trends further, and affects the annual discharge amount from the river. The increasing (positive) trends for annual and monsoon seasonal pattern has been predicted with $5 \%$ of confidence level. Obviously, it is a must to view the monthly trends as it contributes in seasonal pattern of river discharge. The results of predicted monthly trend values show increase in trends (positive) for the month of January, March and September with $10 \%$ of confidence level whereas the month of July, August, November and December shows the increasing (positive trends) along with the $5 \%$ of confidence level.

Table 8. Monthly trend distribution for river discharge

\begin{tabular}{c|c|c|c|c}
\hline \multirow{2}{*}{ S. No } & Murappanadu stream gauge & \multicolumn{3}{|c}{ Monthly statistical analysis } \\
\cline { 2 - 4 } & station & $\mathbf{Z}$ & $\boldsymbol{\rho}$ & Trend \\
\hline $\mathbf{1}$ & January & $2.758^{* * *}$ & $0.392^{* * *}$ & Increasing trend \\
$\mathbf{3}$ & February & 0.012 & 0.027 & No trend \\
$\mathbf{4}$ & March & $1.633^{* * *}$ & $0.305^{* * *}$ & Increasing trend \\
$\mathbf{5}$ & April & 0 & -0.009 & No trend \\
$\mathbf{6}$ & May & -0.23 & -0.053 & No trend \\
$\mathbf{7}$ & June & -1.5 & -0.241 & No trend \\
$\mathbf{8}$ & July & $2.395^{* *}$ & $0.353^{* *}$ & Increasing trend \\
$\mathbf{9}$ & August & $1.802^{* * * *}$ & $0.38^{* *}$ & Increasing trend \\
$\mathbf{1 0}$ & September & -0.012 & -0.004 & Increasing trend \\
$\mathbf{1 1}$ & October & $2.117^{* *}$ & $0.345^{* *}$ & No trend \\
$\mathbf{1 2}$ & November & $2.298^{* *}$ & $0.363^{* *}$ & Increasing trend \\
\hline
\end{tabular}

Level of significance: $* * *=0.10, * *=0.05, *=0.01$

\section{Comparative result analysis of rainfall and river discharge}

According to the non-parametric Mann-Kendall, Spearman's Rho and Linear Regression statistical testing in the annual rainfall analysis, the upstream side of the river basin has one station named Senkottai that is affected by increase (positive) in trend and in the middle of basin with two stations namely; Sankarankoil and Kayathar with increase (positive) in trends while the decreasing (negative) trend have been noticed in downstream side of the basin with station named Tirunelveli has to be investigated with its hydrological parameters for sustainable management of water resources. Simulatneously, the Murappanadu stream gauge station river discharge is facing the positive (increasing) trends due to the impact of rainfall points at its upstream rain gauge stations such as Cheranmahadevi, Senkottai, Kayathar, and Sankarankoil predicting increase (positive) in trends. Therefore, the analysis shows that there is variation in the climate of the basin therefore, the anthropogenic activities responsible for the cause and effect of rainfall have to be inspected in all the five rain gauge stations.

From the analytical point of view, it is observed that the rainfall in all three patterns such as annual, seasonal and monthly have been altered over the long period of time scale i.e., 39 years (1980-2018) which is indicating that there is a slight change in climate that is taking place slowly throughout the basin. The actual morphology of the basin is perennial having sufficient surface and ground water flow in varied flooding condition during its monsoon periods. But this flood conditions are now changing its nature as per 
the observed data due to an erratic rainfall making its impact on the heavy discharge towards the river banks. Therefore, the quantity of rainfall getting its impact in rainfall pattern simultaneously affects the river discharge as extreme events like floods. The change in climate is somewhat visible through the survey that there is an increase in deforestation along the Western Ghats, India (upstream side) as well as industrialization along the downstream side of the basin in terms of local scale. The global increase in Land Surface Temperature (LST) and Sea Surface Temperature (SST) impacts this river basin as it is subjected to both land and sea surfaces in terms of global scale which can be predicted appropriately through climate modelling as scenarios for past present and future conditions.

\section{Micro-level impact study on trend pattern}

To have a clear picture on the trend pattern from the whole basin to block level impact of trend can be predicted through Theissen polygon interpolation method with help of ArcGIS software. This interpolation method helps us to predict the rate of climate change in block level to the whole basin and able to make decision on the management level studies. The spatial representation of block level trend prediction for annual (Fig. 8), and seasonal such as north-east monsoon (Fig. 9a) and summer (Fig. 9b) is shown below and Table 9 indicates the rate of trends with respect to basin blocks respectively. This pictorial representation (Fig. 8) shows that the rainfall stations subjected to the significant trends i.e. positive (increasing) and negative (decreasing) as well as non-significant trends in the whole basin has the capability to calculate the trend rate in percent. Hence, the spatial scale variation as figures for annual (Fig. 8) as well as seasonal (Fig. 9) patterns and the temporal scale of annual trend rate determination tabulated as Table 9 the rate of climate change for the whole basin of Thamirabarani river has been concluded.

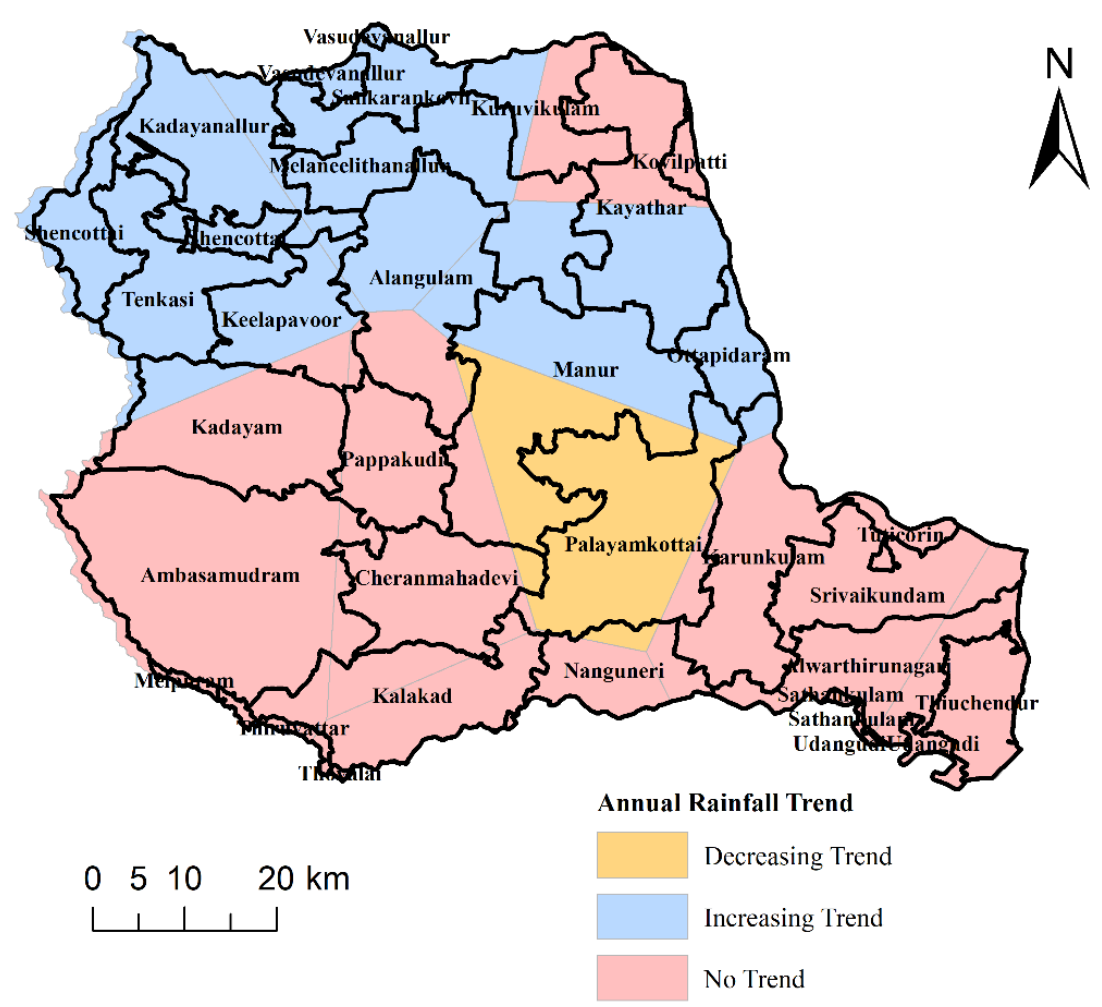

Figure 8. Spatial representation of blocks influenced by annual rainfall trend 
Table 9. Block-level trend analysis on Thamirabarani River basin

\begin{tabular}{c|c|c|c|c|c}
\hline \multirow{2}{*}{ S1. No } & Name of the blocks & \multirow{2}{*}{ Area $\left(\mathbf{k m}^{\mathbf{2}}\right)$} & \multicolumn{3}{|c}{ Trend $\mathbf{( \% )}$} \\
\cline { 3 - 6 } & & Increasing trend & Decreasing trend & No trend \\
\hline $\mathbf{1}$ & Alwathirunagari & 211.64 & - & - & 100 \\
$\mathbf{2}$ & Karunkulam & 260.54 & 6.53 & 1.98 & 91.47 \\
$\mathbf{3}$ & Kayathar & 330.70 & 56.73 & - & 43.27 \\
$\mathbf{4}$ & Kovilpatti & 24.31 & - & - & 100 \\
$\mathbf{5}$ & Ottapidaram & 80.05 & 100 & - & - \\
$\mathbf{6}$ & Sathankulam & 7.16 & - & - & 100 \\
$\mathbf{7}$ & Srivaikundam & 227.85 & - & - & 100 \\
$\mathbf{8}$ & Tiruchendur & 117.27 & - & - & 100 \\
$\mathbf{9}$ & Tuticorin & 31.70 & - & - & 100 \\
$\mathbf{1 0}$ & Udangudi & 22.41 & - & - & 100 \\
$\mathbf{1 1}$ & Alangulam & 326.32 & 68.57 & 2.28 & 29.15 \\
$\mathbf{1 2}$ & Ambasumdram & 589.74 & - & - & 100 \\
$\mathbf{1 3}$ & Cheranmadevi & 218.34 & - & 5.99 & 94.01 \\
$\mathbf{1 4}$ & Kadayam & 291.48 & 15.70 & - & 84.30 \\
$\mathbf{1 5}$ & Kadayanallur & 263.97 & 100 & - & - \\
$\mathbf{1 6}$ & Kalakad & 271.91 & - & - & 100 \\
$\mathbf{1 7}$ & Keelapavoor & 176.79 & 78.74 & - & 21.26 \\
$\mathbf{1 8}$ & Kuruvikulam & 146.32 & 36.19 & - & 63.81 \\
$\mathbf{1 9}$ & Manur & 473.76 & 43.81 & 43.42 & 12.77 \\
$\mathbf{2 0}$ & Meelaneelithanallur & 308.69 & 91.93 & - & 8.07 \\
$\mathbf{2 1}$ & Nanguneri & 140.50 & - & 12.16 & 87.84 \\
$\mathbf{2 2}$ & Palayamkottai & 388.17 & 4.93 & 84.91 & 10.17 \\
$\mathbf{2 3}$ & Papakudi & 157.68 & - & - & 100 \\
$\mathbf{2 4}$ & Sankarankoil & 124.83 & 100 & - & - \\
$\mathbf{2 5}$ & Senkottai & 169.67 & 100 & - & - \\
$\mathbf{2 6}$ & Tenkasi & 203.44 & 100 & - & - \\
$\mathbf{2 7}$ & Vasudevanallur & 330.34 & 100 & - & - \\
$\mathbf{2 8}$ & Melpuram & 7.81 & - & - & 100 \\
$\mathbf{2 9}$ & Thiruvattar & 19.35 & - & - & 100 \\
$\mathbf{3 0}$ & Thovalai & 2.15 & - & - & $\mathbf{6 1 . 5 4 \%}$ \\
\hline & Total blocks & $\mathbf{5 6 2 4 . 9 0}$ km & $\mathbf{3 3 . 4 4 \%}$ & $\mathbf{5 . 0 2 \%}$ & \\
\hline & & & & \\
\hline
\end{tabular}

From Table 9, it is interpreted that these blocks in Thamirabarani River basin are involved in trend analysis. The thirty blocks along with ten rain gauge stations made its interpolation and determined each and every block trend patterns with respect to area of the basin. Therefore, as a result the increasing trend of $33.44 \%$ and decreasing trend of $5.02 \%$ was subjected to significant rate of change in climate along with remaining $61.54 \%$ of non-significant zero trends. This calculated rate of change by trend analysis will be leading to take measures and management in particular sub-watersheds of the whole basin whichever under severe cause. 


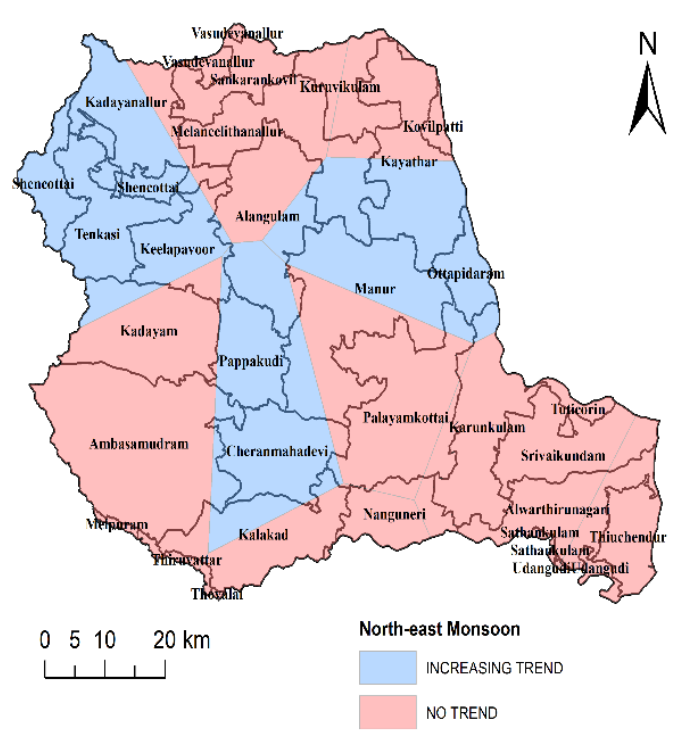

(a) North-east Monsoon (October to December)

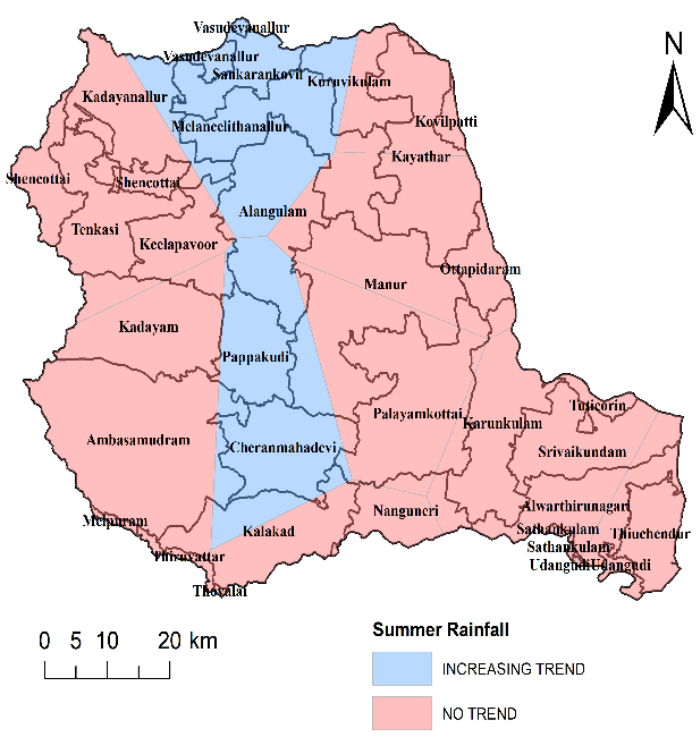

(b) Summer (March to May)

Figure 9. Spatial representation of blocks influenced by seasonal rainfall trend

\section{Conclusion}

With ten rain gauge stations and one stream gauge station, the analysis was done for annual and seasonal rainfall variability as well as annual, seasonal and monthly river discharge variation study in comparison with rainfall and its river discharge for the period of 39 years (1980-2018) in Thamirabarani river basin, Tamilnadu, India. The annual, seasonal and monthly trends are predicted by Mann-Kendall (MK) test, Spearman's Rho (SR) test and Simple linear regression analysis with respective confidence intervals. Out of ten rain gauge stations, the five rain gauge stations are showing both increasing (positive) and decreasing (negative) trends during annual and seasonal periods while in the stream gauge station, the river discharge is showing only increasing (positive) trends throughout the annual, seasonal and monthly patterns. The trend patterns as well as temporal and spatial variability of rainfall and its river discharge clearly shows that the Thamirabarani river basin is under climatic impacts over the period of time. The comparative result of rainfall and river discharge shows that the fluctuations in rainfall range leads to rate of change in river discharge of the basin. With the micro-level study, the blocks taken with respect to rain gauge station throughout the basin by interpolation helps us to understand the trend patterns in terms of climate change rate. Hence, the study concludes that the $33.44 \%$ of increasing trend will make changes in extreme events like flood and $5.02 \%$ of decreasing trend have the probability of creating drought to the basin. The statistical analysis is the preliminary assessment for any river basin study which helps in better hydrological modelling, sustainable water management, agricultural development and economic prosperity of the region. The present study can be initiated as one of the major objective for future work regarding any analysis of hydrological parameters in modelling and software. Also, the statistical results will be oriented towards finding the significance of trends using worse likelihood test for the prediction of return period floods and autocorrelation modelling for weather forecasting. 
Acknowledgements. The authors would like to thank for the use of Trend software availed by eWater Cooperative Research Centre (eWater CRC) and social science statistics online tool.

\section{REFERENCES}

[1] Ahmad, I., Tang, D., Wang, T., Wang, M., Wagan, B. (2015): Precipitation trends over time using Mann-Kendall and Spearman's rho tests in Swat River basin, Pakistan. Advances in Meteorology. https://doi.org/10.1155/2015/431860.

[2] Alifujiang, Y., Abuduwaili, J., Ge, Y. (2021): Trend analysis of annual and seasonal river runoff by using innovative trend analysis with significant test. - Water 13(1): 95.

[3] Anand, B., Karunanidhi, D. (2020): Long term spatial and temporal rainfall trend analysis using GIS and statistical methods in Lower Bhavani basin, Tamil Nadu, India. - Indian Journal of Geo-Marine Sciences 49(3): 419-427.

[4] Bello, Y., Adebayo, A. A., Abubakar, B. (2020): Analysis of rainfall and temperature changes in Gombe State, Nigeria. - FUDMA Journal of Sciences 4(1): 632-646.

[5] Bhaskar, A. S., Hopkins, K. G., Smith, B. K., Stephens, T. A., Miller, A. J. (2020): Hydrologic signals and surprises in US stream flow records during urbanization. - Water Resources Research 56(9): e2019WR027039.

[6] Das, A., Tripathy, B. (2020): Long term assessment of rainfall over different districts of Odisha: a case study. - IOSR Journal of Mechanical and Civil Engineering Volume 17(2) (I): 11-22.

[7] Dawood, M., Rahman, A. U., Ullah, S., Mahmood, S., Rahman, G., Azam, K. (2020): Spatio-statistical analysis of rainfall fluctuation, anomaly and trend in the Hindu Kush region using ARIMA approach. - Natural Hazards 101: 449-464.

[8] Diop, L., Bodian, A., Diallo, D. (2016): Spatiotemporal trend analysis of the mean annual rainfall in Senegal. - European Scientific Journal 12(12): 231-245.

[9] Gajbhiye, S., Meshram, C., Mirabbasi, R., Sharma, S. K. (2016): Trend analysis of rainfall time series for Sindh River basin in India. - Theoretical and Applied Climatology 125(3): 593-608.

[10] Gocic, M., Trajkovic, S. (2013): Analysis of changes in meteorological variables using Mann-Kendall and Sen's slope estimator statistical tests in Serbia. - Global and Planetary Change 100: 172-182.

[11] Hussien, S. A., Mustafa, B. Y., Medhat, F. K. (2019): Trend analysis of annual and monthly rainfall in Erbil City, Kurdistan Region, Iraq. - Polytechnic Journal 9(2): 30-36.

[12] Kale, S. E. M. İ. H., Sönmez, A. Y. (2019): Trend analysis for streamflow of Devrekani Stream (Turkey). - Review of Hydrobiology 12(1-2): 23-37.

[13] Li, Y. Y., Yang, G. S., Wan, R. R., Li, B., Lai, X. J. (2020): Change characteristics of water exchange between the Yangtze River and the Dongting Lake during 1960-2018 in China. - Applied Ecology and Environmental Research 18(2): 3177-3193.

[14] Meshram, S. G., Singh, S. K., Meshram, C., Deo, R. C., Ambade, B. (2018): Statistical evaluation of rainfall time series in concurrence with agriculture and water resources of Ken River basin, Central India (1901-2010). - Theoretical and Applied Climatology 134(3): 1231-1243.

[15] Nikhil Raj, P. P., Azeez, P. A. (2012): Trend analysis of rainfall in Bharathapuzha River basin, Kerala, India. - International Journal of Climatology 32(4): 533-539.

[16] Nyokabi, E. W., Wambua, R. M., Okwany, R. O. (2017): Assessment of rainfall, streamflow and reservoir level trends for Malewa River catchment, Naivasha, Kenya. Journal of Civil, Construction and Environmental Engineering 6(1): 1-8.

[17] Palanichamy, M., Sankaralingam, R. (2020): Statistical studies on rainfall and time-based deviations in precipitation trends in Vaigai River Basin, TN State, India. - Indian Journal of Geo Marine Sciences Volume 49(01): 15-23. 
[18] Pandit, D. V. (2016): Seasonal rainfall trend analysis. - International Journal of Engineering Research and Application 6(7): 69-73.

[19] Rathnayake, U. (2019): Comparison of statistical methods to graphical methods in rainfall trend analysis: case studies from tropical catchments. - Advances in Meteorology. https://doi.org/10.1155/2019/8603586.

[20] Sah, S., Singh, R. N., Chaturvedi, G., Das, B. (2021): Trends, variability, and teleconnections of long-term rainfall in the Terai region of India. - Theoretical and Applied Climatology 143(1): 291-307.

[21] Savo, V., De Zuliani, E., Salvati, L., Perini, L., Caneva, G. (2012): Long-term changes in precipitation and temperature patterns and their possible impacts on vegetation (TolfaCerite Area, Central Italy). - Applied Ecology and Environmental Research 10(3): 243266.

[22] Singh, D., Glupta, R. D., Jain, S. K. (2015): Statistical analysis of long term spatial and temporal trends of temperature parameters over Sutlej River basin, India. - Journal of Earth System Science 124(1): 17-35.

[23] Sobral, B. S., de Oliveira-Júnior, J. F., Alecrim, F., Gois, G., Muniz-Júnior, J. G., de Bodas Terassi, P. M., Pereira-Júnior, E. R., Lyra, G. B., Zeri, M. (2020): PERSIANNCDR based characterization and trend analysis of annual rainfall in Rio De Janeiro State, Brazil. - Atmospheric Research 238: 104873.

[24] Solaimani, K., Habaibnejad, M., Pirnia, A. (2021): Temporal trends of hydro-climatic variables and their relevance in water resource management. - International Journal of Sediment Research 36(1): 63-75.

[25] Talib, M. N. A., Ahmed, M., Naseer, M. M., Slusarczyk, B., Popp, J. (2021): The LongRun impacts of temperature and rainfall on agricultural growth in Sub-Saharan Africa. Sustainability 13(2): 595. 